\title{
Douche Powder Dosage Form
}

National Cancer Institute

\section{Source}

National Cancer Institute. Douche Powder Dosage Form. NCI Thesaurus. Code C69033.

A powder which may be mixed with a liquid, intended for administration as a vaginal

irrigant. 